\title{
Citation Analysis of State Universities in Tamil Nadu
}

\author{
R. Senthilkumar ${ }^{1}$ and G.Ulaganathan ${ }^{2}$ \\ ${ }^{1}$ Librarian (SG) \& Head (Research), Department of Library and Information Science, \\ Kongunadu Arts \& Science College (Autonomous), Coimbatore, Tamil Nadu, India \\ ${ }^{2}$ LIS, Research Scholar Ph.D (PT), Kongunadu Arts \& Science College (Autonomous), \\ Coimbatore-641 029. \& Librarian, Dr.SNS.Rajalakshmi College of Arts \& Science, \\ (Autonomous),Coimbatore, Tamil Nadu, India \\ E-mail: ulaganathan200619711@gmail.com
}

\begin{abstract}
Indian Citation Index database is a powerful tool that let you search, track, measure and collaborate in the sciences, social sciences, arts, and humanities to turns raw data/information into the powerful knowledge you need. A database in general is a collection of information that is organized so that it can easily be accessed for various purposes, managed, and updated regularly. This paper is discussed about the published research articles and its citation from Universities in Tamil Nadu. During period from 2004 to 2014, the maximum no of articles 234(15.03) are published in the year 2012. Among the 234,104(6.68) articles from Bharathiar university, 57(3.66)articles from Bharathidasan university and 73(4.69)periyar University. It clearly shows the authors from BharathiarUniversity are more concentrating on Indian journals

Keywords: Indian Citation Index; Year wise Productivity; Citation Analysis;
\end{abstract}

\section{I.INTRODUCTION}

India is contributing good amount of knowledge but there is no tool for evaluation and measurement of its knowledge. At international level few tools/databases are available but coverage of Indian knowledge contents particularly published in local national journals are negligible. If you can measure that of which you speak, and can express it by a number, you know something of your subject; but if you cannot measure it, your knowledge is meager and unsatisfactory." William Thomson, Lord Kelvin. India is a huge part of the global society, has long and distinguished history as country, possess capability and vital resource to influence, mark presence on the emerging universe of knowledge. Therefore, these tools/databases are not adequate to evaluate/ analyze India's knowledge contents. To resolve similar limitation, few countries, like China, Korea, Japan etc. have already brought out their own citation indexes. Mr. Prakash Chand, Ex Scientist NISCAIR, CSIR and M/s DIVA ENTERPRISES Pvt. Ltd. with a view to address this long felt need have developed and brought out multidisciplinary Indian Citation Index (ICI) by scanning -1000 journals of Indian origin.

\section{A.Indian Citation Index (ICI)}

Indian Citation Index (ICI) is a home grown abstracts and citation database, with multidisciplinary objective information/knowledge contents from about 1000 top Indian scholarly journals. It provides powerful search engine basically to perform search and evaluation for researchers, policy makers, decision makers etc. At present, it is planned to launch this long awaited and needed information tool with five years back files (depth) which would go over 10 years and beyond in a year's time. ICI database is a powerful tool that let you search, track, measure and collaborate in the sciences, social sciences, arts, and humanities to turns raw data/information into the powerful knowledge you need. Indian Citation Index (ICI) database is an abstracts and citation database intended to measure and perform two basic functions, general literature search and evaluation using citations similar to international databases. A database in general is a collection of information that is organized so that it can easily be accessed for various purposes, managed, and updated regularly. Citations symbolize the association of R\&D ideas. The references that researchers cite in their papers make explicit links between their current research and prior work in the literature archive. Indian Citation Index (ICI) use intellectual links by listing both cited and citing works. Like other indexes, this enables one to move back in time to previously published papers. But uniquely one can also look forward in time to determine who has subsequently cited an earlier piece of research. ICI is the abbreviation of "Indian Citation Index "(ICI). It is a multidisciplinary abstract and citation database of journals publish from India. ICI is useful for researchers, administrators, policy makers, editors, librarians and analysts for their respective nature of work.

\section{II.REVIEW OF LITERATURE}

Nicholas and Ritchie ${ }^{1}$ in their books entitled "Literature on Bibliometrics" opined that bibliometrics provided information about the structure of knowledge and how it is communicated? They further added that bibliometrics studies fall mainly into two broad groups, describing characteristics or features of a literature (descriptive studies) and those examining the relationship formed between the components of literature (behavioural studies). More recently, Plotter ${ }^{2}$ had defined bibliometrics as "The study and measurement of the publication patterns of all forms of written communication and their authorship”. Some of the 
recent study on bibliometric study has been reviewed. Mooghali ${ }^{3}$ et al using bibliographic records from the Social Science Citation Index, Science Citation Index, and Arts and Humanities Citation Index, tried to give a complete view of the evolution of the field of Scientometrics based on its literature published during 1980 to 2009.This is a descriptive survey using scientometric indicators .Karpagam 4 et al. analysed the growth pattern of Nanoscience and Nanotechnology literature in India during 1990-2009 (20 years). The Scopus international multi-disciplinary bibliographical database has been used to identify the Indian contributions on the field of Nano science and nanotechnology Abramo ${ }^{5}$ made the study on the development of bibliometric techniques to suggest their integration or total substitution for classic peer review in the national research assessment exercises, as far as the hard sciences are concerned. They compare rankings lists of universities captured by the first Italian evaluation exercise, through peer review, with the results of bibliometric simulations. The comparison shows the great differences between peer review and bibliometric rankings for excellence and productivity Lapon-Kandeishein and Prebor ${ }^{6}$ presented the state of bibliographical research in the discipline of Hebrew printing during a 30-year period, ranging from the latter quarter of the twentieth century until the beginning of the third millennium (1976-2006) Krampen, Eye and Schui ${ }^{7}$ studied bibliometric data on psychology publications from 1977 through 2008 are modelled and forecasted for the 10 years following 2008 Kumar Suchetan ${ }^{8}$ and et. al. S. Dhanavandan and M. Tamizhchelvan $^{9}$ studied Research Productivity And Citations Of Universities In South Tamil Nadu From 2009 To 2013 A Study Based Indian Citation Index (ICI).Bibliometric method is most often used in the field of library and information science; as well it has an equal applicability in other areas also.
In fact, in many research fields use of bibliometric methods is carried out to explore the impact of their field, the impact of a set of researchers, or the impact of a particular paper etc. Bibliometrics are now used in quantitative research assessment exercises of academic output.

\section{III.SCOPE OF THE STUDY}

The main aim of the study is to analysis the research output and its citation by the authors from state universities in Tamil Nadu. It is discussed about the research articles produced by the authors and also shows the citation and cited articles.

\section{IV.OBJECTIVES OF THE STUDY}

Based on the sources the framed objectives are;

1. To identify the year wise publication of article in ICI

2. To know the year wise citation and Cited Articles

3. To identify the subject by highly cited

4. To classify the Document type

\section{V.METHODOLOGY}

Citation analysis is one of the most widely used methods of Bibliometrics. It is the examination of the frequency, patterns, and graphs of citations in articles and books. . This study is aimed to discuss about the analysis of the citation index of the research output by faculty members of University. The relevant sources and data are collected from Indian Citation Index. Based on the available sources the following discussions were made. In this study denotes BU-Bharathiar University,BHU-Bharathidasan University,PU-Periyar University.

\section{VI.ANALYSIS AND INTERPRETATION}

TABLE I YEAR WISE DISTRIBUTION OF ARTICLES

\begin{tabular}{|c|c|c|c|c|}
\hline Year & BU & BHU & PU & Total \\
\hline 2004 & $35(2.25)$ & $30(1.93)$ & $1(0.06)$ & $66(4.24)$ \\
\hline 2005 & $38(2.44)$ & $47(3.02)$ & $5(0.32)$ & $90(5.78)$ \\
\hline 2006 & $23(1.48)$ & $34(2.18)$ & $11(0.71)$ & $68(4.37)$ \\
\hline 2007 & $29(1.86)$ & $39(2.50)$ & $22(1.41)$ & $90(5.77)$ \\
\hline 2008 & $21(1.35)$ & $37(2.38)$ & $25(1.60)$ & $83(5.33)$ \\
\hline 2009 & $36(2.31)$ & $59(3.79)$ & $29(1.86)$ & $124(7.96)$ \\
\hline 2010 & $67(4.30)$ & $73(4.69)$ & $65(4.17)$ & $205(13.16)$ \\
\hline 2011 & $82(5.26)$ & $64(4.11)$ & $73(4.69)$ & $219(14.06)$ \\
\hline 2012 & $104(6.68)$ & $57(3.66)$ & $73(4.69)$ & $234(15.03)$ \\
\hline 2013 & $91(5.84)$ & $47(3.02)$ & $59(3.79)$ & $197(12.65)$ \\
\hline 2014 & $81(5.20)$ & $44(2.82)$ & $57(3.66)$ & $182(11.68)$ \\
\hline Total & $607(38.96)$ & $531(34.08)$ & $420(26.96)$ & $1558(100)$ \\
\hline
\end{tabular}




\section{Articles}

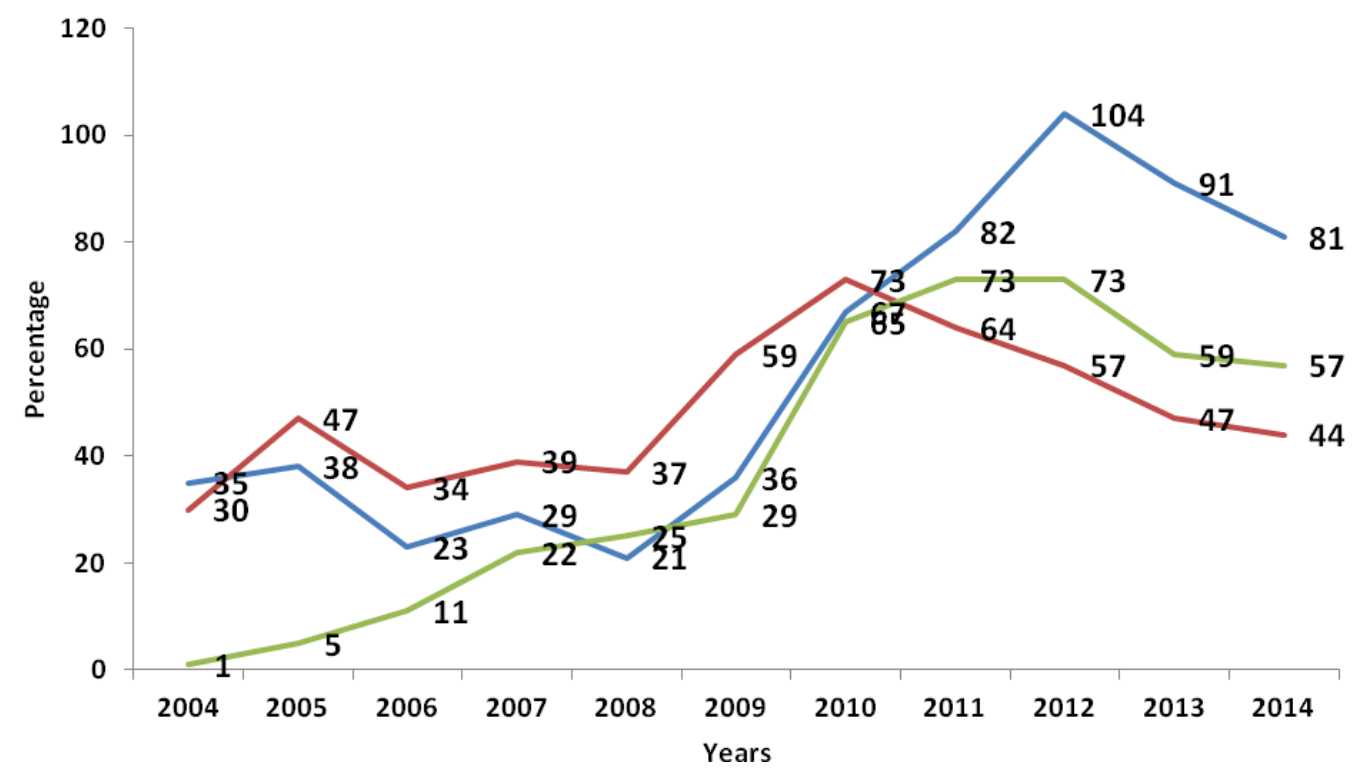

Fig.1Year wise Distribution of Articles

TABLE II YEAR WISE DISTRIBUTION OF CITED ARTICLES

\begin{tabular}{|c|c|c|c|c|}
\hline Year & BU & BHU & PU & Total \\
& & & & \\
\hline 2004 & $9(3.03)$ & $13(4.38)$ & $1(0.34)$ & $23(7.75)$ \\
\hline 2005 & $10(3.37)$ & $16(5.39)$ & $1(0.34)$ & $27(9.10)$ \\
\hline 2006 & $5(1.68)$ & $12(4.04)$ & $3(1.01)$ & $20(6.73)$ \\
\hline 2007 & $4(1.35)$ & $13(4.38)$ & $2(0.67)$ & $19(6.40)$ \\
\hline 2008 & $4(1.35)$ & $9(3.03)$ & $8(2.69)$ & $21(7.07)$ \\
\hline 2009 & $10(3.37)$ & $14(4.71)$ & $9(3.03)$ & $33(11.11)$ \\
\hline 2010 & $19(6.40)$ & $18(6.06)$ & $12(4.04)$ & $49(16.50)$ \\
\hline 2011 & $13(4.38)$ & $10(3.37)$ & $15(5.05)$ & $38(12.80)$ \\
\hline 2012 & $16(5.39)$ & $8(2.69)$ & $11(3.70)$ & $35(11.78)$ \\
\hline 2013 & $10(3.37)$ & $4(1.35)$ & $10(3.37)$ & $24((8.09)$ \\
\hline 2014 & $1(0.34)$ & $0(0)$ & $7(2.36)$ & $8(2.70)$ \\
\hline Total & $101(34.01)$ & $117(39.39)$ & $79(26.60)$ & $297(100)$ \\
\hline
\end{tabular}

Table II states the year wise distribution of various cited article from Universities from Tamil Nadu. From the year 2004 to 2014 nearly 297 cited articles were identified from Indian Citation Index. Among the297, 23(7.75) cited articles from 2004, the maximum number of 49(16.50)cited articles from 2010, the minimum number of 8(2.70)cited articles form 2014, It is clearly shows from the year 2011 the cited articles rate is in the decreasing order.

Table 3 indicates the year wise distribution of articles published by the various authors from Universities in Tamil Nadu. During the year 2004to 2014, 1558 articles were published which are indexed in Indian Citation Index. Among the 1558, in the year 2004, 66 articles were published by three universities. But the maximum no of article,234 in the year 2012. Among the 234, 104 articles from Bharathiar university, 73 articles from Periyar University and 57 Bharathidasan University. In the part of citations during the period 706 citations were identified from Indian Citation Index. Among the 706, 199 from Bharathiar University, 333 from Bharathidasan University and 174 from Periyar University citations were identified. It is clearly shows less number(45.31\%) of articles were cited. 


\section{Cited Articles}

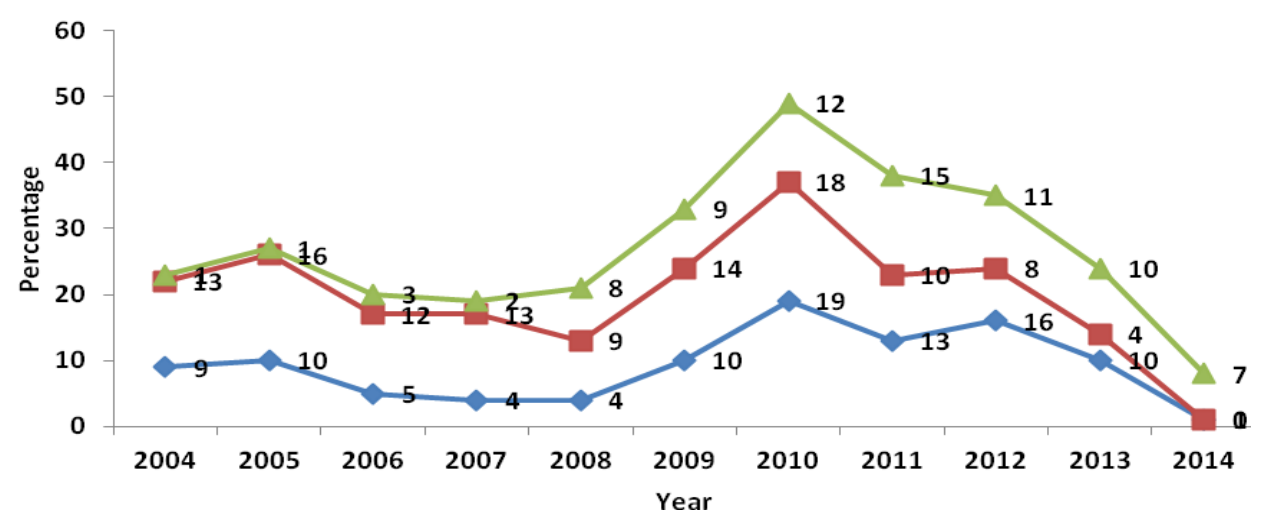

Fig.2 Year wise Distribution of Cited Articles

TABLE III YEAR WISE DISTRIBUTION OF ARTICLES AND CITATIONS

\begin{tabular}{|c|c|c|c|c|c|c|c|c|}
\hline & \multicolumn{5}{|c|}{ Article } & \multicolumn{4}{c|}{ Citation } \\
\hline $\begin{array}{c}\text { Year/ } \\
\text { University }\end{array}$ & BU & BHU & PU & TOTAL & BU & BHU & PU & TOTAL \\
\hline 2004 & 35 & 30 & 1 & 66 & 21 & 33 & 4 & 58 \\
\hline 2005 & 38 & 47 & 5 & 90 & 25 & 47 & 6 & 78 \\
\hline 2006 & 23 & 34 & 11 & 68 & 7 & 21 & 8 & 36 \\
\hline 2007 & 29 & 39 & 22 & 90 & 5 & 86 & 2 & 93 \\
\hline 2008 & 21 & 37 & 25 & 83 & 9 & 25 & 31 & 65 \\
\hline 2009 & 36 & 59 & 29 & 124 & 18 & 25 & 23 & 66 \\
\hline 2010 & 67 & 73 & 65 & 205 & 39 & 56 & 27 & 122 \\
\hline 2011 & 82 & 64 & 73 & 219 & 22 & 27 & 24 & 73 \\
\hline 2012 & 104 & 57 & 73 & 234 & 26 & 9 & 22 & 57 \\
\hline 2013 & 91 & 47 & 59 & 197 & 26 & 4 & 17 & 47 \\
\hline 2014 & 81 & 44 & 57 & 182 & 1 & 0 & 10 & 11 \\
\hline Total & 607 & 531 & 420 & 1558 & 199 & 333 & 174 & 706 \\
\hline Average & 55.18 & 48.27 & 38.18 & 141.64 & 18.09 & 30.27 & 15.82 & 64.18 \\
\hline
\end{tabular}

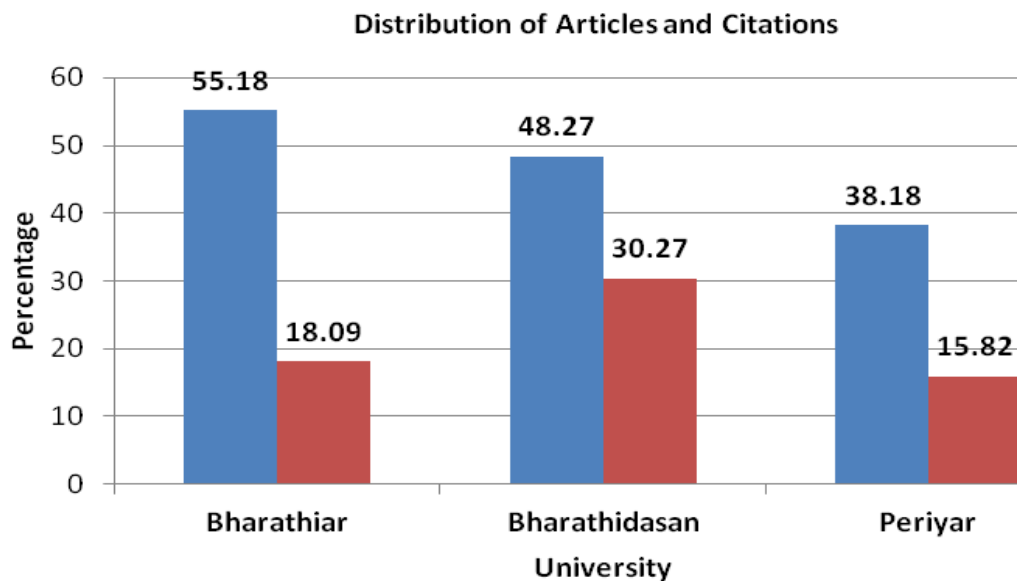

Fig.3 Year wise Distribution of Articles and Citations 
TABLE IV YEAR WISE DISTRIBUTION OF ARTICLES AND CITED ARTICLES

\begin{tabular}{|c|c|c|c|c|c|c|c|c|}
\hline \multirow{2}{*}{$\begin{array}{c}\text { Year/ } \\
\text { University }\end{array}$} & \multicolumn{4}{|c|}{ Articles } & \multicolumn{5}{c|}{ Cited Articles } \\
\cline { 2 - 10 } & BU & BHU & PU & TOTAL & BU & BHU & PU & TOTAL \\
\hline 2004 & 35 & 30 & 1 & 66 & 9 & 13 & 1 & 23 \\
\hline 2005 & 38 & 47 & 5 & 90 & 10 & 16 & 1 & 27 \\
\hline 2006 & 23 & 34 & 11 & 68 & 5 & 12 & 3 & 20 \\
\hline 2007 & 29 & 39 & 22 & 90 & 4 & 13 & 2 & 19 \\
\hline 2008 & 21 & 37 & 25 & 83 & 4 & 9 & 8 & 21 \\
\hline 2009 & 36 & 59 & 29 & 124 & 10 & 14 & 9 & 33 \\
\hline 2010 & 67 & 73 & 65 & 205 & 19 & 18 & 12 & 49 \\
\hline 2011 & 82 & 64 & 73 & 219 & 13 & 10 & 15 & 38 \\
\hline 2012 & 104 & 57 & 73 & 234 & 16 & 8 & 11 & 35 \\
\hline 2013 & 91 & 47 & 59 & 197 & 10 & 4 & 10 & 24 \\
\hline 2014 & 81 & 44 & 57 & 182 & 1 & 0 & 7 & 8 \\
\hline Total & 607 & 531 & 420 & 1558 & 101 & 117 & 79 & 297 \\
\hline Average & 55.18 & 48.27 & 38.18 & 141.64 & 9.18 & 10.64 & 7.18 & 27.00 \\
\hline
\end{tabular}

Distribution of Articles and Cited Articles

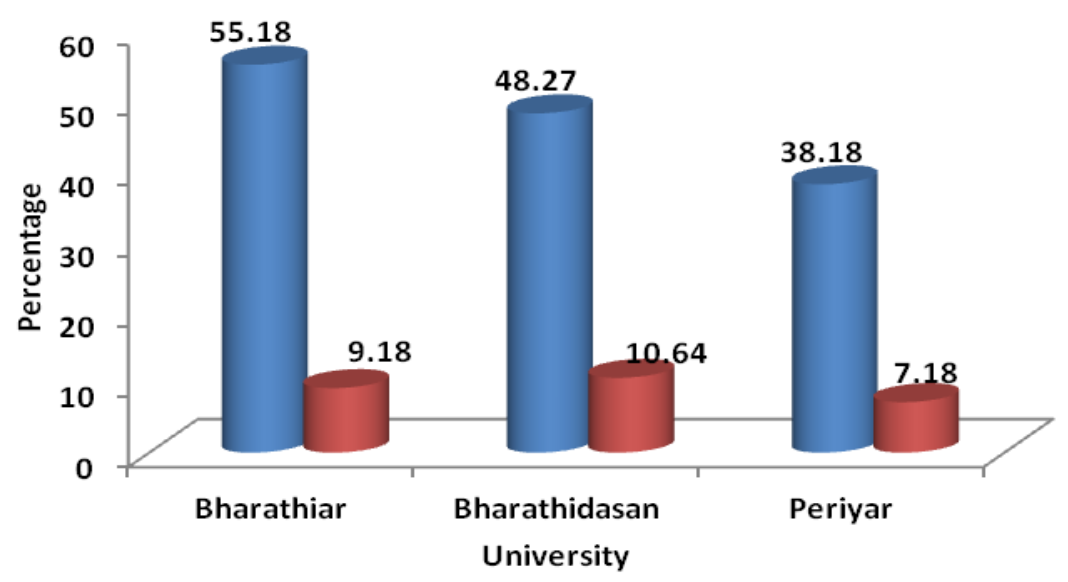

Fig.4 Year wise Distribution of Articles and Cited

Table IV indicates the year wise distribution of articles and cited articles by various authors from Universities from Tamil Nadu. It is considered for the last Eleven years from 2004 to 2014. The highest no. of citations 234 were identified in the year 2012. From the year 2004 to 2014 nearly 297cited articles were identified from Indian Citation Index. It is clearly shows from the year 2011 the cited articles rate is in the decreasing order.

\section{VII.CONCLUSION}

Indian Citation Index is increase the visibility of and access to other library resources. It provides users to search peer-reviewed and highly used contents publish in local national journals. ICI is useful for researchers, administrators, policy makers, editors, librarians and analysts for their respective nature of work. So, the library professionals are make the necessary arrangement to bring out knowledge and utilization Indian Citation Index and its benefits to end user community. The maximum no of articles 234(15.03) are published in the year 2012. Among the 234, 04(6.68) articles from Bharathiar university, 57(3.66) articles from Bharathidasan university and 73(4.69) periyar University. It clearly shows the authors from Bharathiar University are more concentrating on Indian journals. The maximum number of 49(16.50)cited articles from 2010, the minimum number of8(2.70)cited articles form 2014, It is clearly shows from the year 2011 the cited articles rate is in the decreasing order. During the period 706 citations were identified from Indian Citation Index. Among the 706, 199 from Bharathiar University, 333 from Bharathidasan University and 174 from Periyar University citations were identified. It is clearly shows less number (45.31\%) of articles were cited. The highest no. of 
citations 234 were identified in the year 2012. From the year 2004 to 2014 nearly 297cited articles were identified from Indian Citation Index. It is clearly shows from the year 2011 the cited articles rate is in the decreasing order.

\section{REFERENCES}

[1] Nicholas David and Ritchie Maureen. Literature and Bibliometrics. London: Clive Bingley, (1978).

[2] Potter W.G., Introduction to bibliometrics, Library Trends, 30, 5, (1981) http://www.myjurnal.my/filebank/published_article 17760/4.pdf .

[3] Mooghali A. et al. Scientometric Analysis of the Scientometric Literature, International Journal of Information Science and Management, 9(1), 19-31 (2011) .
[4] Karpagam R. et al. Mapping of Nano science and nanotechnology research in India: a scientometric analysis, 1990-2009, Scientometrics, 89(2), 501-522 (2011)

[5] Abramo Giovanni, National research assessment exercises: a comparison of peer review and bibliometrics rankings. Scientometrics, 89(3), 929-941 (2011).

[6] Lapon-Kandelshein, Esther and Prebor, Gilla, Bibliographical research in the study of Hebrew printing: a bibliometric analysis, Scientometrics, 88(3), 899-913 (2011).

[7] Krampen G., Eye A. and Schui G., Forecasting trends of development of psychology from a bibliometric perspective, Scientometrics, 87(3), 687-694 (2011) .

[8] Kumar suchetan, Tiwari Charu and Deepu Mahija, contribution to Indian sociology: A Bibliometric study, Language in India, (2012) http://www.lang

[9] 9.S. Dhanavandan and M. Tamizhchelvan, Research Productivity and Citations of Universities in South Tamil Nadu From 2009 To 2013 A Study Based Indian Citation Index (ICI): International Journal of Digital Library Services ,4(2), 109-116 (2014). 